(c) 2017, THE AUTHORS. Published by FASS and Elsevier Inc. on behalf of the American Dairy Science Association ${ }^{\circledR}$.

This is an open access article under the CC BY-NC-ND license (http://creativecommons.org/licenses/by-nc-nd/3.0/).

\title{
Locomotion characteristics of dairy cows walking on pasture and the effect of artificial flooring systems on locomotion comfort
}

\author{
M. Alsaaod, ${ }^{* 1}$ S. Huber, ${ }^{*}$ G. Beer, ${ }^{*}$ P. Kohler, ${ }^{*}$ G. Schüpbach-Regula, $\dagger$ and A. Steiner* \\ ${ }^{*}$ Clinic for Ruminants, Vetsuisse-Faculty, and \\ †Veterinary Public Health Institute, Vetsuisse-Faculty, University of Bern, 3001 Bern, Switzerland
}

\begin{abstract}
The locomotion comfort of dairy cows depends on the floor of the walking alleys. Optimal locomotion comfort is given when cows walk on pasture, allowing freedom from discomfort and pain and the expression of normal behavior. This study examined the characteristics of locomotion behavior on pasture (gold standard with optimal locomotion comfort) and compared it with behaviors of cows walking on mastic asphalt or solid rubber mats before and after a routine claw trimming session. Our hypotheses were (1) that gait variables were different on pasture versus mastic asphalt and on mastic asphalt versus rubber, and (2) that claw trimming had an effect on gait variables of cows walking on mastic asphalt. Twenty-four dairy cows kept in a tiestall facility were enrolled in this experimental trial. The pedogram was measured using 2 standalone 3 -dimensional accelerometers $(400 \mathrm{~Hz})$, attached to the metatarsus of both hind limbs. The extracted pedogram variables included temporal events (kinematic outcome = gait cycle and stance-phase and swing-phase durations) and peaks (kinetic outcome $=$ foot load, toe-off). The cows were further video-recorded to calculate walking speed and stride length. Locomotion score was performed on mastic asphalt to enroll only nonlame cows (locomotion score $<3$ ). For comparison between different floor types, repeated-measures ANOVA was performed with the cow as a subject variable, session time of measurement as within-subject variable, and flooring type as a fixed effect. Three separate analyses were performed: pasture versus mastic asphalt (analysis I), solid rubber versus mastic asphalt (analysis II), and the effect of claw trimming on the kinematic and kinetic variables on mastic asphalt (analysis III). All tested gait variables were significantly different between pasture and mastic asphalt floor. The optimal characteristics of locomotion comfort on pasture included shorter dura-
\end{abstract}

Received February 20, 2017.

Accepted June 3, 2017.

${ }^{1}$ Corresponding author: maher.alsaaod@vetsuisse.unibe.ch tion of gait cycle, longer stance-phase duration, shorter swing-phase duration, higher walking speed, longer stride length, and higher peaks of foot load and toe-off. However, gait variables of cows walking on rubber mats did not show any significant difference compared with the mastic asphalt floor; only stride length tended to be longer on rubber mats. In addition, the stance- and swing-phase durations significantly improved shortly after trimming. The left-right differences of the stanceand swing-phase durations tended to decrease after claw trimming when cows walked on asphalt floor. The results of this study show that solid rubber flooring does not result in significant improvement of the evaluated variables of locomotion comfort compared with mastic asphalt.

Key words: dairy cow, gait cycle, floor, accelerometer

\section{INTRODUCTION}

Lameness and foot pathologies in dairy cattle constitute a major welfare concern. Lameness prevalence ranges from 14.8\% in Switzerland (Becker et al., 2014) to $54.8 \%$ in the northeastern United States (von Keyserlingk et al., 2012). Lameness in cattle is an expression of pain that negatively affects animal welfare and causes considerable economic losses for the dairy producers (Whay et al., 2003; Bruijnis et al., 2010).

Most research on cow comfort and lameness control in loose housing systems has focused on flooring surface design, because of the direct contact of the feet with the floor (Nordlund and Cook, 2003; Chapinal et al., 2011; Charlton et al., 2016). Poor flooring can affect animal welfare by impairing normal locomotion and thus increasing the risk of lameness and foot disorders (Telezhenko and Bergsten, 2005; van der Tol et al., 2005; Rushen and de Passillé, 2006). Telezhenko (2007) defined the term "locomotion comfort" as the condition of well-being and contentment in the walking areas. According to his definition, optimal locomotion comfort implies "natural gait and activity" and "good condition of the locomotor apparatus" of the animals in the long term (Telezhenko, 2007). Pasture is the 
most comfortable floor for the claws as it provides the optimal balance of the claw horn wear and growth and a natural claw load (Tranter and Morris, 1992). Access to pasture is reported to be beneficial in reducing lameness and the risk of cows being affected by claw disorders compared with zero-grazing herds (Somers et al., 2003; Regula et al., 2004; Hernandez-Mendo et al., 2007). Because of the increasing use of zero-grazing systems and automated milking systems, the access to pasture of cows in many European countries is declining sharply (Ipema, 2015).

In the literature, results describing the effect of floor characteristics on claw health are inconsistent. Haufe et al. (2009) reported a slight effect of floor type (solid rubber, mastic asphalt, and slatted concrete floor) on claw health, whereas Vanegas et al. (2006) reported that foot lesions did not differ between floor types, although locomotion score was higher for concrete-exposed cows than for those on rubber. In contrast, Kremer et al. (2007) and Fjeldaas et al. (2011) reported a higher incidence of sole ulcers for rubber-exposed cows compared with those on concrete.

Concrete and mastic asphalt are hard floors and have been associated with an increased incidence of lameness and foot disorders (Vokey et al., 2001; Cook et al., 2004), due to greater load and pressure on the claw structures (van der Tol et al., 2002) causing slipping and "stiff" gait (Phillips and Morris, 2000). Soft walking surfaces such as solid rubber flooring have become increasingly popular alternatives to hard floors in the walking area of dairy facilities. A soft floor may reduce the pressure on the foot (Nuss et al., 2015) and potentially improve cow comfort (Platz et al., 2008), and may thus reduce the incidence of lameness (Vanegas et al., 2006). However, it has also been shown that cows on rubber flooring have decreased horn wear compared with cows kept on concrete (Vanegas et al., 2006). Functional claw trimming in dairy cows is performed as a routine management procedure to prevent the development of claw disorders (Manske et al., 2002).

The objective measurement of cow gait on different flooring surfaces may allow the differentiation between floors with minimal comfort and those with good locomotion comfort. The characteristics of impaired locomotion due to lameness in dairy cattle include stride shortening, stiff gait (Flower and Weary, 2006), reduced walking speed (Chapinal et al., 2011; Beer et al., 2016), and decreased foot load and time of weightbearing (Rajkondawar et al., 2006; Van Nuffel et al., 2013; Alsaaod et al., 2017b). Three-dimensional (3D) accelerometers attached to both hind limbs can detect (1) alterations associated with lameness and foot pathologies of the hind limbs (Alsaaod et al., 2017b), and (2) changes in gait while walking on different flooring surfaces (Chapinal et al., 2011). For example, Chapinal et al. (2011) investigated the changes in acceleration between different flooring surfaces and showed a difference in asymmetry of variance of cattle walking on rubber versus concrete flooring, in which the variance of acceleration was higher on concrete than on rubber mats.

The aims of the current study were (1) to describe the characteristics of locomotion behavior of nonlame cows on pasture (gold standard with optimal locomotion comfort), using commercially available high frequency (400 Hz) 3D accelerometers and video-recording; (2) to compare gait characteristics on pasture with those exhibited by cows walking on mastic asphalt or rubber mats, and (3) to determine the effect of claw trimming of the hind limbs on kinematic and kinetic variables in cows walking on mastic asphalt. Our hypotheses were that gait variables were different between pasture and mastic asphalt and between mastic asphalt and rubber, and that claw trimming had an effect on gait variables of cows walking on mastic asphalt.

\section{MATERIALS AND METHODS}

\section{Ethics Statement}

The study protocol was approved by the animal experimentation committee of the canton of Bern, Switzerland (permission \# 25162).

\section{Animals, Housing and Claw Trimming}

The study was carried out on 24 dairy cows of an agricultural school (Inforama Rütti, Zollikofen, Switzerland) between January and April. The sample size of 24 cows was calculated to detect an effect size of 0.6 at a power of $80 \%$ and a confidence level of $5 \%$. An online calculator for paired $t$-test was used for the sample size calculation (https://www.anzmtg.org/stats/ PowerCalculator/PowerTtest). The cows were housed in a tiestall facility and kept on rubber mats covered with straw bedding. The cows were allowed daily access to pasture during the grazing season (April to October) and weekly access to an outside yard (mastic asphalt) during the winter feeding season (November to March).

The mean age of the cows was 3.5 yr (range: $2-7.5$ yr), the mean lactation number 2 (range: $1-5$ ) and the mean DIM was $164(4-338)$ at the beginning of the study. The breeds involved were Holstein Friesian ( $\mathrm{n}=$ $2)$, Red Holstein $(\mathrm{n}=17)$, and Swiss Fleckvieh $(\mathrm{n}=$ 5). Mean $305-\mathrm{d}$ milk yield was $7,925 \mathrm{~kg}$. Claw trimming was performed according to a standardized protocol by one professional claw trimmer, using an angle grinder (Lischer et al., 2014). All claws were trimmed. Infec- 
tious foot disorders (IFD) were treated by the claw trimmer according to standardized procedures, digital dermatitis by the application of Intra Hoof-fit Gel (IntraCare BV, Haaften, the Netherlands), and heel horn erosion by pasting wood tar on the affected horn. The frequency of claw trimming was twice a year. At claw trimming, all foot lesion data were documented by the first author, using the claw data documentation software Klauenmanager, version 3.1 (SEG Informationstechnik, Bad Ischl, Austria; Kofler, 2013). The hind feet were classified as either healthy (nonlesion group, $\mathrm{n}=11)$ or affected with IFD $(\mathrm{n}=13)$. The IFD group included feet with a moderate degree of heel horn erosion $(\mathrm{n}=13$; V-shaped fissures or craters of the heel or bulb not affecting corium) as described by Sogstad et al. (2006), digital dermatitis ( $\mathrm{n}=4$; stages M1 to M4, as described by Döpfer et al., 1997), or a combination of these lesions. Noninfectious lesions included white line disease $(n=2)$ and sole hemorrhage $(n=3)$. All noninfectious lesions were superficial, had a severity score of "slight," and were completely removed by functional claw trimming without touching the pododerma, and were, therefore, classified as healthy.

\section{Experimental Procedures and Flooring Types}

The cows were encouraged to freely walk along an artificial passageway $(1.5 \mathrm{~m}$ wide $\times 15 \mathrm{~m}$ long). An animal caretaker walked behind the cows at a distance of approximately $2 \mathrm{~m}$, encouraging the individual cow to walk without pause. The cows were filmed with a digital video camera (50 frames/s; Sony HDR-PJ740VE, Sony Corp., Tokyo, Japan) placed at a distance of 10 $\mathrm{m}$ from the passageway. The time sample of the accelerometers and the video camera had previously been synchronized to the time sample of a PC to match data recordings from both pieces of equipment. Two flooring types were tested in the same artificial passageway: mastic asphalt in wk -1 and $+1,+3,+5,+7$ relative to claw trimming and solid rubber (including both waiting areas at the beginning and end of the walkway) in wk $+1,+3$, and +5 , each time $1 \mathrm{~d}$ after the evaluation on mastic asphalt.

The rubber mats were $24 \mathrm{~mm}$ thick, $119 \mathrm{~cm}$ long, and $85 \mathrm{~cm}$ wide, with puzzle-shaped borders (Type Kura G; now called Kura Flex, Gummiwerke Kraiburg, Germany), as these are the most commonly used soft floors of the walking area of freestall facilities worldwide (P. Unternaehrer, DeLaval AG, Sursee, Switzerland; personal communication). The third investigated surface was pasture (gold standard) with the same dimensions of the artificial passageway and tested in wk +7 relative to claw trimming. As the pasture in wk $+1,+3$, and +5 was frozen, we performed the measurement only in wk +7 relative to claw trimming. The pasture floor was neither frozen nor muddy and was free from stones of relevant size or any barriers; the measurement was conducted at an environmental temperature of $22^{\circ} \mathrm{C}$. Cows were individually trained and habituated by walking at least 6 passages on each flooring type on each recording day before data acquisition to ensure adequate adaption to the investigated floor.

Slip resistance of the mastic asphalt (outside yard and passageway) was measured with a slip resistance tester (Deutsche Landwirtschafts-Gesellschaft e.V. and Agroscope, Tänikon, Switzerland) as described previously by Steiner et al. (2011). Briefly, 12 randomly selected areas of both the outside yard and the passageway were measured after cleaning and subsequent wetting the measured areas. The median of the slip resistance $(\mu)$ was 0.30 (range: $0.25-0.33)$ and $0.37(0.32-0.39)$ for outside yard and passageway, respectively. The measured values of the passageway were within the reference values $(0.3-0.5 \mu)$ of mastic asphalt used for housing of dairy cows (Steiner et al., 2011).

\section{Recording and Analysis of Gait Variables}

On each experimental day, immediately before data recording, cows were equipped with 2 standalone 3D accelerometers (400 Hz; USB Accelerometer X16-4; Gulf Coast Data Concept, Waveland, MS), which were fitted at the level of the metatarsus to both hind limbs. The gait cycle variables were extracted using the validated Cow-Gait-Analyzer (University of Bern, Switzerland) as described by Alsaaod et al. (2017a). Table 1 lists all gait variables, including gait cycle and video variables, and the definitions used in this study. For each individual cow, the mean value of each variable, separately for pasture, mastic asphalt, or solid rubber, was calculated by averaging the values of both limbs (parts I, II, and III) and additionally as the mean difference between hind limbs for the pedogram variables of part III).

Two markers separated by $7.97 \mathrm{~m}$ were painted on the walls of the passageway in all 3 investigated floors. The walking speed $(\mathrm{m} / \mathrm{s})$ was calculated as $7.97 \mathrm{~m}$ divided by the time (s) spent from the moment the nose of the cow passed the start mark until it passed the end mark. The average stride length $(\mathrm{m})$ was calculated from the marked distance per walk divided by the number of strides per walk. Half a stride was added if the cow did not completely perform the whole stride within the marked distance. The stride length was defined as the distance between 2 consecutive foot strikes of the same hind limb. When the cow was running, stopping, slipping, jumping, or defecating during measurements, 
Table 1. Gait variables including gait cycle variables extracted by use of the Cow-Gait-Analyzer as described by Alsaaod et al. (2017a) and video variables

\begin{tabular}{|c|c|}
\hline Gait variable & Definition \\
\hline Gait cycle duration (s) & Interval between 2 consecutive foot-load peaks \\
\hline Swing phase $(\%)$ & $\begin{array}{l}\text { Proportion of time (\%) that the foot is not in contact with the ground to the total gait cycle duration } \\
\text { (interval between toe-off peak and consecutive foot-load peak) }\end{array}$ \\
\hline Foot load $(g)$ & Maximum peak of the initial ground contact of the foot \\
\hline Stride length $(\mathrm{m})$ & Distance between 2 consecutive foot strikes of the same hind limb \\
\hline Walking speed (m/s) & Stride length/stride duration \\
\hline
\end{tabular}

data of the respective walk were discarded. When the cow defecated on the passageway, the manure was immediately removed.

\section{Clinical Gait Score Assessment}

The video recordings were blinded as to group (IFD or healthy) allocation, and locomotion was scored by the first author (MA) using a 1-5 numerical rating system (NRS; where $1=$ nonlame and $5=$ severely lame) based on 6 specific gait attributes (back arch, head bob, tracking up, joint flexion, asymmetric steps, and reluctance to bear weight; Flower and Weary, 2006). Cows with an NRS $\geq 3$ were classified as lame. At wk +3 and $+5,2$ lame cows (NRS $\geq 3$ ) were observed and consequently excluded from further analyses (analyses I and II). Only nonlame cows were enrolled in the study.

\section{Data Analysis and Statistics}

The normality of gait variables was checked with the Shapiro W statistics. The majority of data were not normally distributed; therefore, a natural logarithm was calculated for normality data distribution (Shapiro W test statistic for all variables was $>0.95$ ). The transformed variables were analyzed using the software package $\mathrm{NCSS}^{10}$ (NCSS LLC, Kaysville, UT). For comparison between different floor types, repeatedmeasures ANOVA was performed with the cow as a subject variable, week relative to claw trimming and foot pathologies as within-subject variables, and flooring type as a fixed effect. Three separate analyses were performed. Analysis I = pasture versus mastic asphalt $($ wk $+7 ; \mathrm{df}=21)$ and pasture $(\mathrm{wk}+7)$ versus solid rubber $(\mathrm{wk}+1,+3,+5$ and +8 ; $\mathrm{df}=20)$; analysis II $=$ solid rubber versus mastic asphalt in $\mathrm{wk}+1,+3$, and $+5(\mathrm{df}=2)$; and analysis III = effect of claw trimming and IFD on kinematic and kinetic variables in wk -1 vs. wk $+1(\mathrm{df}=23)$ relative to claw trimming on mastic asphalt. We did not analyze the effect of
IFD in analyses I and II, as we did not examine the claws in the trimming chute at these points in time. A Bonferroni-corrected $P$-value was calculated to account for multiple comparisons; the significance value was set at $P \leq 0.05$ and the tendency level at $P \leq 0.1$ (without Bonferroni adjustment). All data presented in Table 2 represent nontransformed data.

\section{RESULTS}

\section{Characteristics of Locomotion Comfort on Pasture}

Data of the various gait variables when the cows were walking on pasture at wk +7 are given in Table 2. Walking on pasture revealed significant differences for all gait variables compared with walking on mastic asphalt. The variables of optimal locomotion comfort on pasture were characterized by lower duration of the gait cycle, longer stance-phase duration, shorter swing-phase duration, higher walking speed, longer stride length, and higher peaks of foot load and toe-off compared with locomotion on mastic asphalt (Table 2 ). Walking on pasture on wk +7 showed significant differences for the stance phase, swing phase and foot load compared with walking on rubber mats in wk +1 , $+3+5$, and +8 . Except for stride length, there was an interaction between session time of measurement and floor type on locomotion characteristics considering pasture $(\mathrm{wk}+7)$ and rubber mats $(\mathrm{wk}+1,+3,+5$, and $+8 ; P \leq 0.05)$.

\section{Mastic Asphalt Versus Solid Rubber Mats}

In wk $+1,+3$, and +5 , gait variables were not significantly different on rubber mats and mastic asphalt (Table 2). Only stride length revealed a tendency to be longer on rubber mats than on mastic asphalt $(P=$ 0.083 ). There was no interaction between session and floor type on the locomotion characteristics in $\mathrm{wk}+1$, +3 , or $+5(P>0.05)$. 


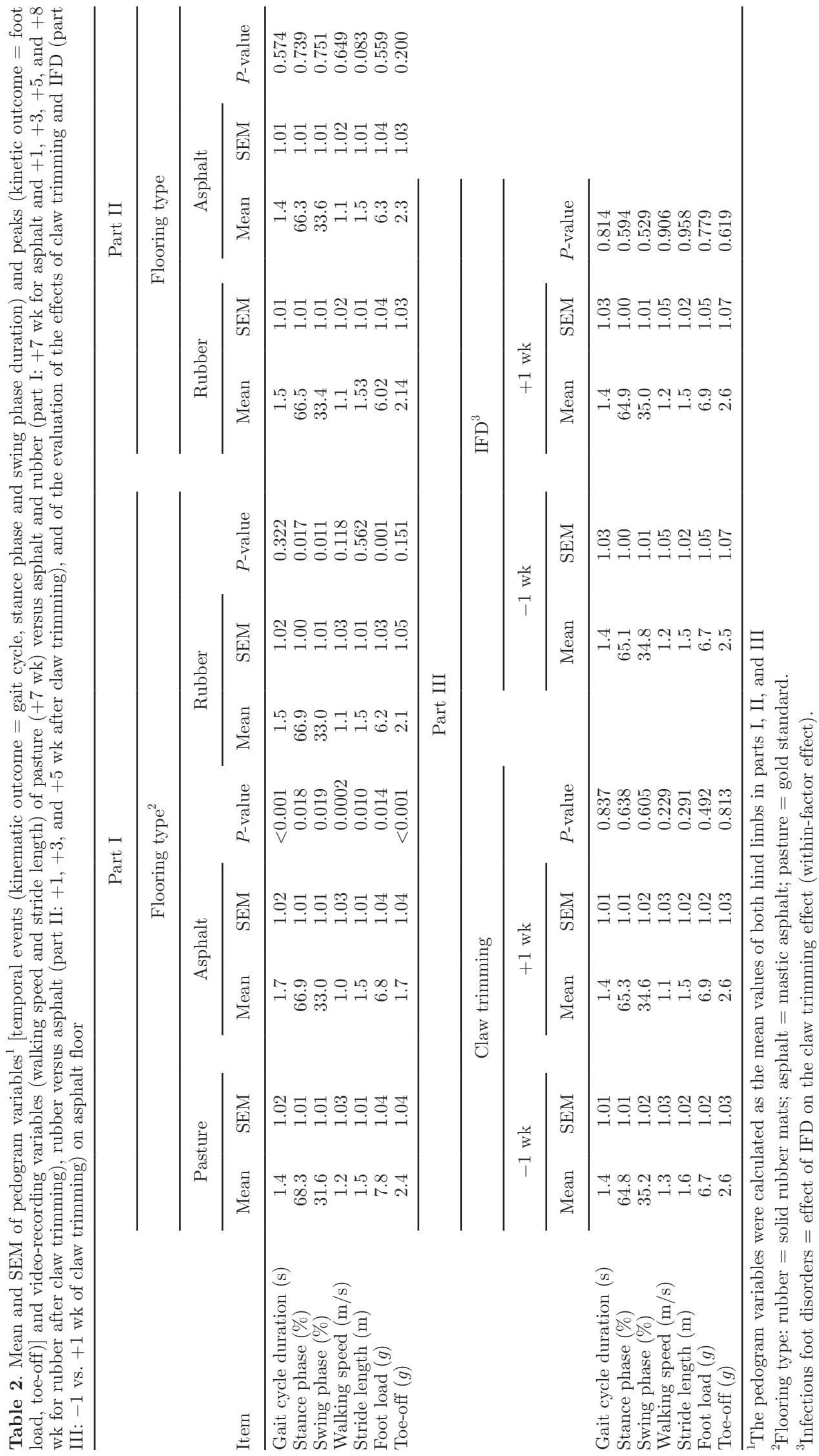




\section{Effect of Claw Trimming and IFD}

We did not detect an effect of claw trimming or IFD on the various gait variables of cows walking on mastic asphalt $(P>0.05)$. The left-right differences of the stance- and swing-phase durations tended to decrease after claw trimming when cows walked on asphalt floor $(1.5 \% \pm 1.02 \mathrm{in} \mathrm{wk}-1$ and $1.2 \% \pm 1.02$ in wk +1 ; both $P=0.069)$.

\section{DISCUSSION}

The results of this study showed that, compared with mastic asphalt, rubber flooring does not result in a significant improvement of the evaluated variables of locomotion comfort that are present in dairy cows on pasture. Claw trimming did not have any significant effect on locomotion characteristics of cows walking on mastic asphalt.

Although flooring characteristics are known to be a risk factor for foot and limb disorders (Somers et al., 2003; Platz et al., 2008; Bergsten et al., 2015), little is known about the effect of the floor type on gait variables to assess locomotion comfort in dairy cattle. To the best of our knowledge, this is the first description of gait characteristics as a means to assess the locomotion comfort on pasture compared with that on mastic asphalt. The investigated results were used as a basis to estimate the gait changes on rubber mats compared with pasture. Furthermore, we used the combination of video-recording variables and validated pedogram analysis.

In part I of the analysis, cows walking on pasture (gold standard) showed significant differences for all pedogram and video-recording variables compared with mastic asphalt. Kinetic variables (foot load and toeoff) were higher on pasture than on mastic asphalt or rubber mats, indicating that cows showed more confidence when walking on pasture. It seems reasonable to assume that pasture, as a natural floor, allows the claws to sink into the floor and thus generates more traction. The longer stance phase, longer stride length, and higher walking speed indicate easy movement and comfortable walking on pasture. Frequent pasturing is an important management measure to improve the locomotion comfort of dairy cows. Walking on pasture showed significant differences for the stance phase, swing phase, and foot load compared with walking on rubber mats. These results should be interpreted with caution because the measurements of pasture and rubber mats were performed at different time points, and some significant interactions between session and floor type considering pasture $(\mathrm{wk}+7)$ and rubber mats ( $\mathrm{wk}$
$+1,+3,+5$, and +8$)$ were evident for various locomotion characteristics.

Most studies have investigated the effect of rubber and concrete floors on cow gait, as these represent the most common flooring types installed in dairy farms. Previous studies reported that cows kept on rubber mats generally showed greater activity and they stood in the walking area longer than cows on mastic asphalt or slatted concrete floor (Kremer et al., 2007; Haufe et al., 2009).

The defined characteristics of locomotion comfort on pasture in this study were used as a basis to estimate the improvement of cow walking on solid rubber mats compared with mastic asphalt (part II of the analysis). Cows walking on rubber mats showed no significant difference for any gait variables compared with those walking on mastic asphalt. It seems rational to assume that rubber mats do not provide adequate traction and, therefore, do not allow for a similar degree of easy movement compared with pasture. In agreement, Flower et al. (2007) reported no difference in stance or swing time of nonlame cows walking on rubber versus concrete flooring. Telezhenko and Bergsten (2005), Flower et al. (2007), and Chapinal et al. (2011) investigated the walking speed $(\mathrm{m} / \mathrm{s})$ on different flooring systems and found that cows walked faster on rubber than on concrete flooring.

In the current study, only stride length tended to be longer on rubber mats than on mastic asphalt (1.53 vs. $1.49 \mathrm{~m}$ ). This is in agreement with previous studies showing that nonlame cows had longer stride length on rubber than on concrete flooring (Telezhenko and Bergsten, 2005; Flower et al., 2007; Platz et al., 2008; Franco-Gendron et al., 2016) or mastic asphalt (Haufe et al., 2009). Furthermore, the stride length in our study was within the range of 1.54 to $1.57 \mathrm{~m}$ previously reported for nonlame cows walking on rubber (Telezhenko and Bergsten, 2005; Flower et al., 2007). Unfortunately, a comparison of mastic asphalt and concrete was not performed in our study.

The kinematic and kinetics measurements were performed at the level of the hind limbs, because foot disorders and signs of lameness occur more commonly in hind feet in cattle (Solano et al., 2016). Functional claw trimming is a routine method of assessing claw disorders and, at the same time, improving claw conformation and preventing the development of further claw disorders (Manske et al., 2002). Thorup et al. (2014) found improvement of left-right 3D curve symmetry after trimming compared with before trimming using 3D force plates. In the current study, we found no effect of IFD on the kinetic and kinematic characteristics of the hind limbs. The left-right differences of the stance- and 
swing-phase durations tended to decrease after claw trimming when cows walked on asphalt floor. Many studies reported that foot pathologies at certain stages (slight to moderate degree) do not affect the gait score of cows (Engel et al., 2003; Tadich et al., 2010). Furthermore, we excluded lame cows from the analysis, as a previous study showed that lame cows have different walking patterns on different floor types (Flower et al., 2007). The evaluation of the effects of claw trimming on gait score were performed only on mastic asphalt because we (1) expected the effect of claw trimming to be most pronounced on mastic asphalt, and (1) lameness assessment is routinely performed on hard surfaces (Sprecher et al., 1997).

\section{CONCLUSIONS}

The results of this study show that measuring gait variables at pasture, using accelerometers with a high sampling rate $(400 \mathrm{~Hz})$ in parallel with video-recording, is a promising approach to define the characteristics of locomotion comfort in dairy cows. Cows walking on pasture showed distinct differences for all evaluated gait variables compared with cows walking on mastic asphalt. An improvement in the characteristics of locomotion comfort on rubber mats compared with mastic asphalt was not significant in the evaluated variables of locomotion comfort. The indoor flooring systems of rubber mats and mastic asphalt that are currently available for dairy cows do not offer locomotion comfort similar to that of pasture that is not frozen, not muddy, and free from stones of relevant size.

\section{ACKNOWLEDGMENTS}

This study was generously supported by grants of the "Fondation Sur-La-Croix" (Basel, Switzerland).

\section{REFERENCES}

Alsaaod, M., R. Kredel, B. Hofer, and A. Steiner. 2017a. Technical note: Validation of a semi-automated software tool to determine gait cycle variables in dairy cows. J. Dairy Sci. 100:4897-4902. https://doi.org/10.3168/jds.2016-12235.

Alsaaod, M., M. Luternauer, J. T. Hausegger, R. Kredel, and A. Steiner. 2017b. The cow pedogram - Analysis of the gait cycle variables allows for detection of lameness and foot pathologies. J. Dairy Sci. 100:1417-1426.

Becker, J., A. Steiner, S. Kohler, A. Koller-Bahler, M. Wuthrich, and M. Reist. 2014. Lameness and foot lesions in Swiss dairy cows: I. Prevalence. Schweiz. Arch. Tierheilkd. 156:71-78.

Beer, G., M. Alsaaod, A. Starke, G. Schuepbach-Regula, H. Muller, P. Kohler, and A. Steiner. 2016. Use of extended characteristics of locomotion and feeding behavior for automated identification of lame dairy cows. PLoS One 11:e0155796.

Bergsten, C., E. Telezhenko, and M. Ventorp. 2015. Influence of soft or hard floors before and after first calving on dairy heifer locomotion, claw and leg health. Animals (Basel) 5:662-686.
Bruijnis, M. R., H. Hogeveen, and E. N. Stassen. 2010. Assessing economic consequences of foot disorders in dairy cattle using a dynamic stochastic simulation model. J. Dairy Sci. 93:2419-2432.

Chapinal, N., A. M. de Passille, M. Pastell, L. Hanninen, L. Munksgaard, and J. Rushen. 2011. Measurement of acceleration while walking as an automated method for gait assessment in dairy cattle. J. Dairy Sci. 94:2895-2901.

Charlton, G. L., V. Bouffard, J. Gibbons, E. Vasseur, D. B. Haley, D. Pellerin, J. Rushen, and A. M. de Passille. 2016. Can automated measures of lying time help assess lameness and leg lesions on tiestall dairy farms? Appl. Anim. Behav. Sci. 175:14-22.

Cook, N. B., T. B. Bennett, and K. V. Nordlund. 2004. Effect of free stall surface on daily activity patterns in dairy cows with relevance to lameness prevalence. J. Dairy Sci. 87:2912-2922.

Döpfer, D., A. Koopmans, F. A. Meijer, I. Szakall, Y. H. Schukken, W. Klee, R. B. Bosma, J. L. Cornelisse, A. J. van Asten, and A. A. ter Huurne. 1997. Histological and bacteriological evaluation of digital dermatitis in cattle, with special reference to spirochaetes and Campylobacter faecalis. Vet. Rec. 140:620-623.

Engel, B. G. Bruin, G. Andre, and W. Buist. 2003. Assessment of observer performance in a subjective scoring system: Visual classification of the gait of cows. J. Agric. Sci. 140:317-333.

Fjeldaas, T., A. Sogstad, and O. Osteras. 2011. Locomotion and claw disorders in Norwegian dairy cows housed in freestalls with slatted concrete, solid concrete, or solid rubber flooring in the alleys. J. Dairy Sci. 94:1243-1255.

Flower, F. C., A. M. de Passille, D. M. Weary, D. J. Sanderson, and J. Rushen. 2007. Softer, higher-friction flooring improves gait of cows with and without sole ulcers. J. Dairy Sci. 90:1235-1242.

Flower, F. C., and D. M. Weary. 2006. Effect of hoof pathologies on subjective assessments of dairy cow gait. J. Dairy Sci. 89:139-146.

Franco-Gendron, N., R. Bergeron, W. Curilla, S. Conte, T. DeVries, and E. Vasseur. 2016. Investigation of dairy cattle ease of movement on new methyl methacrylate resin aggregate floorings. J. Dairy Sci. 99:8231-8240.

Haufe, H. C., L. Gygax, B. Steiner, K. Friedli, M. Stauffacher, and B. Wechsler. 2009. Influence of floor type in the walking area of cubicle housing systems on the behaviour of dairy cows. Appl. Anim. Behav. Sci. 116:21-27.

Hernandez-Mendo, O., M. A. G. von Keyserlingk, D. M. Veira, and D. M. Weary. 2007. Effects of pasture on lameness in dairy cows. J. Dairy Sci. 90:1209-1214.

Ipema, B. 2015. Application of neck-collar mounted sensor for recording feeding and grazing behaviour. In: 12 . Internationale Tagung: Bau, Technik und Umwelt in der landwirtschaftlichen Nutztierhaltung, Freising 2015. KTBL Darmstadt, Germany.

Kofler, J. 2013. Computerised claw trimming database programs as the basis for monitoring hoof health in dairy herds. Vet. J. 198:358-361.

Kremer, P. V., S. Nueske, A. M. Scholz, and M. Foerster. 2007. Comparison of claw health and milk yield in dairy cows on elastic or concrete flooring. J. Dairy Sci. 90:4603-4611.

Lischer, C., A. Steiner, H. Geyer, K. Friedli, P. Ossent, and K. Nuss. 2014. Klauenpflege (Handbuch zur Klauenpflege beim Rind). 4th ed. rev. Edition lmz, Zollikofen, Switzerland.

Manske, T., J. Hultgren, and C. Bergsten. 2002. The effect of claw trimming on the hoof health of Swedish dairy cattle. Prev. Vet. Med. 54:113-129.

Nordlund, K., and N. B. Cook. 2003. A flowchart for evaluating dairy cow freestalls. Bovine Pract. 37:89-96.

Nuss, K., T. Wiestner, A. Bruderer, and S. Hartnack. 2015. Pressure distribution of claws of lactating cows standing on different types of flooring. Page 98 in Proc. 10th Int. Conf. Lameness in Ruminants. Valdivia, Chile. Universidad Austral de Chile, Valdivia, Chile.

Phillips, C. J. C., and I. D. Morris. 2000. The locomotion of dairy cows on concrete floors that are wet, dry or covered with slurry of excreta. J. Dairy Sci. 83:1767-1772.

Platz, S., F. Ahrens, J. Bendel, H. H. D. Meyer, and M. H. Erhard. 2008. What happens with cow behavior when replacing concrete 
slatted floor by rubber coating: A case study. J. Dairy Sci. 91:9991004.

Rajkondawar, P. G., M. Liu, R. M. Dyer, N. K. Neerchal, U. Tasch, A. M. Lefcourt, B. Erez, and M. A. Varner. 2006. Comparison of models to identify lame cows based on gait and lesion scores, and limb movement variables. J. Dairy Sci. 89:4267-4275.

Regula, G., J. Danuser, B. Spycher, and B. Wechsler. 2004. Health and welfare of dairy cows in different husbandry systems in Switzerland. Prev. Vet. Med. 66:247-264.

Rushen, J., and A. M. de Passillé. 2006. Effects of roughness and compressibility of flooring on cow locomotion. J. Dairy Sci. 89:29652972.

Sogstad, A. M., O. Østeras, and T. Fjeldaas. 2006. Bovine claw and limb disorders related to reproductive performance and production diseases. J. Dairy Sci. 89:2519-2528.

Solano, L., H. W. Barkema, S. Mason, E. A. Pajor, S. J. LeBlanc, and K. Orsel. 2016. Prevalence and distribution of foot lesions in dairy cattle in Alberta, Canada. J. Dairy Sci. 99:6828-6841.

Somers, J. G. C. J., K. Frankena, E. N. Noordhuizen-Stassen, and J. H. M. Metz. 2003. Prevalence of claw disorders in Dutch dairy cows exposed to several floor systems. J. Dairy Sci. 86:2082-2093.

Sprecher, D. J., D. E. Hostetler, and J. B. Kaneene. 1997. A lameness scoring system that uses posture and gait to predict dairy cattle reproductive performance. Theriogenology 47:1179-1187.

Steiner, B., M. Zähner, and M. Keck. 2011. Rutschfestigkeit von Rinderstallböden-Folgerungen für neue Materialien. Bautagung Raumberg-Gumpenstein 2011. Lehr- und Forschungszentrum Raumberg-Gumpenstein, Irdning, Austria.

Tadich, N., E. Flor, and L. Green. 2010. Associations between hoof lesions and locomotion score in 1098 unsound dairy cows. Vet. J. 184:60-65.

Telezhenko, E. 2007. Effect of flooring system on locomotion comfort in dairy cows: Aspects of gait, preference and claw condition. $\mathrm{PhD}$ Thesis. Swedish University of Agricultural Sciences (SLU), Skara, Sweden.

Telezhenko, E., and C. Bergsten. 2005. Influence of floor type on the locomotion of dairy cows. Appl. Anim. Behav. Sci. 93:183-197.
Thorup, V. M., O. F. do Nascimento, F. Skjoth, M. Voigt, M. D. Rasmussen, T. W. Bennedsgaard, and K. L. Ingvartsen. 2014. Short communication: Changes in gait symmetry in healthy and lame dairy cows based on 3-dimensional ground reaction force curves following claw trimming. J. Dairy Sci. 97:7679-7684.

Tranter, W. P., and R. S. Morris. 1992. Hoof growth and wear in pasture-fed dairy cattle. N. Z. Vet. J. 40:89-96.

van der Tol, P. P. J., J. H. M. Metz, E. N. Noordhuizen-Stassen, W. Back, C. R. Braam, and W. A. Weijs. 2002. The pressure distribution under the bovine claw during square standing on a flat substrate. J. Dairy Sci. 85:1476-1481.

van der Tol, P. P. J., J. H. M. Metz, E. N. Noordhuizen-Stassen, W. Back, C. R. Braam, and W. A. Weijs. 2005. Frictional forces required for unrestrained locomotion in dairy cattle. J. Dairy Sci. 88:615-624.

Van Nuffel, A., J. Vangeyte, K. C. Mertens, L. Pluym, S. De Campeneere, W. Saeys, and S. Van Weyenberg. 2013. Exploration of measurement variation of gait variables for early lameness detection in cattle using the GAITWISE. Livest. Sci. 156:88-95.

Vanegas, J., M. Overton, S. L. Berry, and W. M. Sischo. 2006. Effect of rubber flooring on claw health in lactating dairy cows housed in free-stall barns. J. Dairy Sci. 89:4251-4258.

Vokey, F. J., C. L. Guard, H. N. Erb, and D. M. Galton. 2001. Effects of alley and stall surfaces on indices of claw and leg health in dairy cattle housed in a free-stall barn. J. Dairy Sci. 84:2686-2699.

von Keyserlingk, M. A. G., A. Barrientos, K. Ito, E. Galo, and D. M. Weary. 2012. Benchmarking cow comfort on North American freestall dairies: Lameness, leg injuries, lying time, facility design, and management for high-producing Holstein dairy cows. J. Dairy Sci. 95:7399-7408.

Whay, H. R., D. C. J. Main, L. E. Green, and A. J. F. Webster. 2003. Assessment of the welfare of dairy cattle using animal-based measurements: Direct observations and investigation of farm records. Vet. Rec. 153:197-202. 